ARTICLE

DOI: $10.1038 /$ s41467-018-03213-z

\title{
A regulatory circuit of two IncRNAs and a master regulator directs cell fate in yeast
}

\author{
Fabien Moretto ${ }^{1}$, N. Ezgi Wood ${ }^{2}$, Gavin Kelly (1) ${ }^{1}$, Andreas Doncic ${ }^{2,3}$ \& Folkert J. van Werven ${ }^{1}$
}

Transcription of long noncoding RNAs (IncRNAs) regulates local gene expression in eukaryotes. Many examples of how a single IncRNA controls the expression of an adjacent or nearby protein-coding gene have been described. Here we examine the regulation of a locus consisting of two contiguous IncRNAs and the master regulator for entry into yeast meiosis, IME1. We find that the cluster of two IncRNAs together with several transcription factors form a regulatory circuit by which IME1 controls its own promoter and thereby promotes its own expression. Inhibition or stimulation of this unusual feedback circuit affects timing and rate of IME1 accumulation, and hence the ability for cells to enter meiosis. Our data demonstrate that orchestrated transcription through two contiguous IncRNAs promotes local gene expression and determines a critical cell fate decision.

\footnotetext{
${ }^{1}$ The Francis Crick Institute, 1 Midland Road, London NW1 1AT, UK. ${ }^{2}$ Department of Cell Biology, UT Southwestern Medical Center, 6000 Harry Hines Boulevard, Dallas, TX 75390, USA. ${ }^{3}$ Green Center for Systems Biology, UT Southwestern Medical Center, 6001 Forest Park Road, Dallas, TX 75390, USA. Correspondence and requests for materials should be addressed to F.W. (email: folkert.vanwerven@crick.ac.uk)
} 
E xpression of long noncoding RNAs (lncRNAs) influences local gene expression ${ }^{1-7}$. This process is conserved across species. A widespread mechanism through which lncRNAs modulate the expression of adjacent genes is by means of transcription-coupled chromatin changes ${ }^{2,7-11}$. Numerous examples of how a single lncRNA alters the expression of a nearby gene have been described ${ }^{1,2,6,12-15}$. Whether loci of two or more contiguous lncRNAs exist and how they regulate local gene expression remains unexplored.

Meiosis is central to gametogenesis during which a diploid cell gives rise to haploid gametes ${ }^{16}$. In Saccharomyces cerevisiae or budding yeast, the decision to enter meiosis is controlled by the master regulator transcription factor, $I M E 1^{17-19}$. Transcription of $I M E 1$ is tightly controlled by mating-type and nutrient signals ${ }^{19}$. In the presence of nitrogen and fermentable carbon sources, $I M E 1$ is repressed via PKA and TORC signaling pathways ${ }^{20}$. During nutrient starvation, however, expression of IME1 is induced in diploid cells and as a consequence cells enter meiosis.

Transcription of lncRNAs governs mating-type control of entry into meiosis in yeast ${ }^{2}$. In cells with a haploid mating type, transcription of the lncRNA IRT1, encompassing almost the complete IME1 promoter, represses IME1 expression via transcription-coupled chromatin changes ${ }^{2}$. In diploid cells, the transcriptional activator of $I R T 1, R M E 1$, is repressed by the a1a2 repressor complex. This ensures that only cells expressing both mating types (MATa and MATa) can undergo meiosis. Interestingly, a large fraction of yeast natural isolates displays Rme1 expression in diploid cells suggesting that IRT1 may also be active in this cell type $\mathrm{e}^{21-23}$. Previous work suggested that a second lncRNA is expressed further upstream in the IME1 promoter directly adjacent to $I R T 1^{2,24}$. The purpose of this transcript is not understood.

Here we examine how a cluster consisting of two lncRNAs and IME1 controls entry into meiosis. We find that transcription of two contiguous lncRNAs facilitates a regulatory circuit through which IME1 promotes its own expression and meiotic entry. Our results demonstrate how a locus of contiguous lncRNAs can interact in a non-intuitive manner to define a positive feedback loop that drives the decision to enter an important cell differentiation program. The work broadens the spectrum by which transcription of lncRNAs controls local gene expression.

\section{Results}

Two contiguous lncRNAs are expressed in the IME1 promoter. Previous work showed that in cells with a single mating-type $I M E 1$ expression repressed by transcription through the IME1 promoter of the lncRNA IRT1. A second lncRNA, named MUT1523 or IRT2, annotated upstream in the IME1 promoter directly adjacent to $I R T 1$, and expressed in the same direction as $I M E 1$ and IRT1 was reported (Fig. 1a and Supplementary Fig. 1a) 2,24 . This transcript is about $400 \mathrm{bp}$ and expressed in diploid cells during starvation. To examine whether IRT2 is detectable by conventional northern or reverse transcription (RT)-PCR methods, we first measured its expression pattern in diploid cells of strain backgrounds that undergo meiosis proficiently (SK1) and poorly $(\text { S288C })^{21}$. We used SK1 because cells from this strain background enter meiosis synchronously, which makes the use of population-based assays possible for the study of meiotic regulatory mechanisms. In SK1, IRT2 was detectable by northern blot in diploid cells exposed to sporulation medium (SPO), which induces cells to enter meiosis (Fig. $1 \mathrm{~b}$ and Supplementary Fig. $1 \mathrm{a}-\mathrm{c})$. When we further examined the expression pattern in relation to the meiotic program, we found that IRT2 was expressed prior and during meiotic divisions (Supplementary Fig. 1b, c). In S288C, IRT2 expression was also clearly detected at
8 and $24 \mathrm{~h}$ in SPO by RT-PCR (Fig. 1c). We conclude that a second IncRNA, IRT2, is expressed in the IME1 promoter in diploid cells during meiotic entry.

IRT1 and IRT2 control meiotic entry. The expression of IME1 is critical for entry into meiosis in yeast ${ }^{17,18}$. Diploid cells that do not induce IME1 expression will not enter meiosis. Given that IRT1 and IRT2 are localized in the IME1 promoter, we next examined how their expression affects the propensity for cells to enter meiosis. We generated strains where RME1, the activator of $I R T 1$, was deleted $($ rme $1 \Delta)$ and where IRT2 was expressed from an inducible promoter $(p C U P-I R T 2,+\mathrm{Cu})^{2,25}$ (Fig. 1d). This set of mutants allowed us to dissect how IRT1 and IRT2 control entry into meiosis. In S288C, the fraction of cells that completed at least one meiotic division increased in the $r m e 1 \Delta$ (35\% compared to $21 \%$ for the control) suggesting that $I R T 1$ is also active in diploid cells (Fig. 1e). Furthermore, when pCUP-IRT2 was expressed, a comparable increase in meiotic cells was observed (Fig. 1e). Conversely, in the absence of IRT2, ( $p C U P-I R T 2,-\mathrm{Cu})$ the fraction of cells that underwent meiosis decreased (11\% compared to $21 \%$ for the control). These data show that expression of IRT1 represses meiosis, whereas expression of IRT2 promotes meiosis.

In budding yeast, the a1 2 repressor complex, expressed in diploid cells from the opposite mating-type loci (MATa and $M A T \alpha)$, represses $R M E 1$ and accordingly $I R T 1$ expression with variable degree among yeast isolates ${ }^{22,23}$. SK1 harbors the RME1 (del-308A) allele relative to S288C, which creates an additional canonical a1a2 repressor binding site ${ }^{21}$. This causes efficient $R M E 1$ repression and thereby increases the ability of SK1 diploid cells to enter meiosis. Hence, rme1s had a minor effect on meiosis in SK1 (Fig. 1f). Induction of $p C U P$-IRT2 expression also marginally affected meiosis in SK1 cells suggesting that IRT1 is needed for IRT2 function. To examine the relation between IRT1 and IRT2 further, we mutated the a1 22 repressor binding sites in the $R M E 1$ promoter $(R M E 1-H)$ in SK1 cells, which de-represses RME1 expression ${ }^{2,25}$ (Fig. 1d). Consequently, IRT1 expression was increased and the fraction of cells entering meiosis reduced (75\% compared to $14 \%$ for the control) (Fig. If and Supplementary Fig. 2a). Cells harboring $R M E 1-H$ completed meiosis with a reduced efficiency when IRT2 was repressed ( $p C U P-I R T 2,-\mathrm{Cu})$ compared to cells harboring the wild-type IRT2 promoter $(4 \%$ compared to $14 \%$ for the control) (Fig. 1f). Importantly, induction of IRT2 ( $p C U P-I R T 2,+\mathrm{Cu})$ suppressed the meiotic phenotype caused by the RME1-H almost completely $(70 \%$ compared to $14 \%$ for the control). It is worth noting that deleting IRT2 also disrupted the IRT1 promoter, and therefore was not suitable for studying IRT2 function on its own (Supplementary Fig. 2b). We conclude that inhibitory effect of IRT1 expression on meiosis can be suppressed by expressing IRT2.

IRT2 promotes IME1 expression by repressing IRT1. Having established that IRT2 suppresses the effect of IRT1 on meiotic entry, we next examined how IRT2 influences IRT1 and IME1 expression directly. Given that the IRT2 transcript covers two Rme1-binding sites directly upstream of $I R T 1$, we hypothesized that IRT2 transcription interferes with the binding of Rmel and thereby represses IRT1 (Fig. 1a). To test this directly, we expressed IRT2 from an inducible promoter ( $p C U P-I R T 2)$ in cells that also express Rme1 (RME1-H) (Fig. 1d). We found that in the absence of IRT2 ( $p C U P-I R T 2,-\mathrm{Cu}), I R T 1$ levels were constant, whereas transcription of IRT2 strongly inhibited IRT1 accumulation (Fig. 2a). Rme1 almost completely disassociated from the IME1 promoter in the presence of IRT2 (Fig. 2b). As a consequence, IME1 expression was induced, cells underwent meiosis with faster kinetics, and more cells completed meiosis 
a

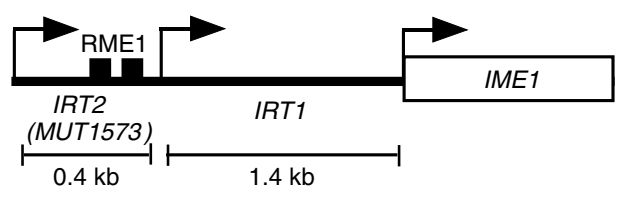

b

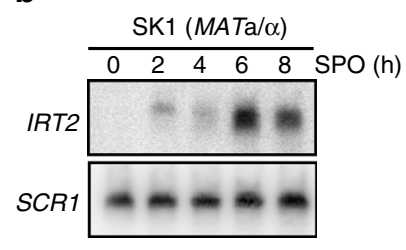

C

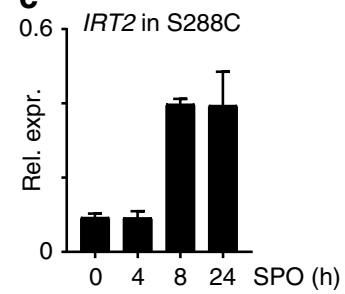

d
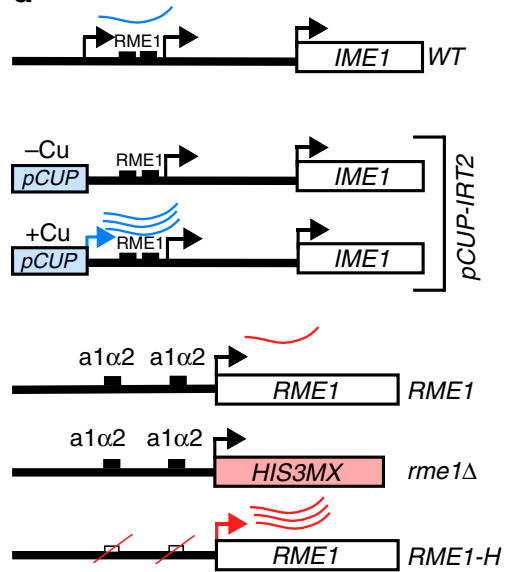

e

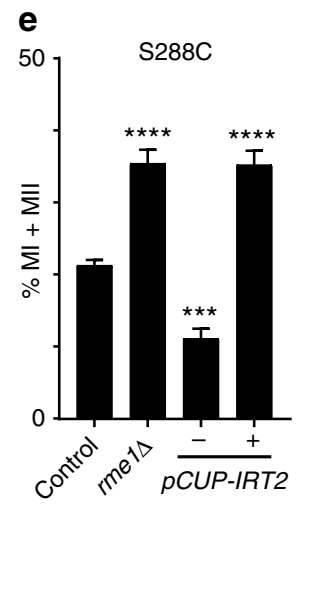

f

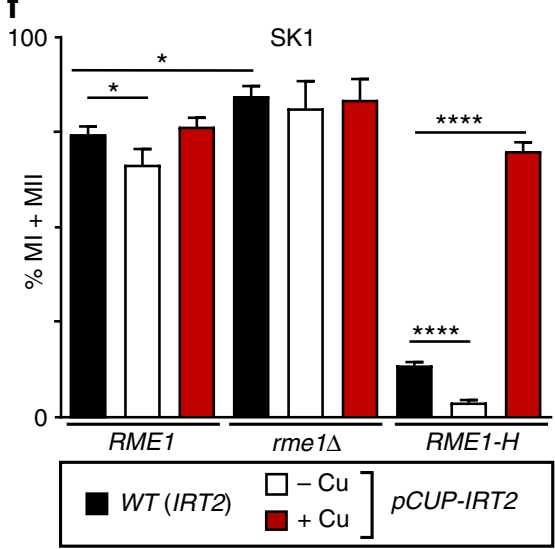

Fig. 1 Transcription of IRT2 promotes entry into meiosis. a Scheme of the IME1 locus consisting of: IRT1, IRT2/MUT1573, and the IME1 gene. b IRT2 expression in SK1 diploid cells (FW1511) during entry into meiosis. Cells were grown in rich medium till saturation, shifted and grown in pre-sporulation medium for another $16 \mathrm{~h}$, and transferred to sporulation medium (SPO). Samples for northern blot were taken at the indicated time points. A probe directed to the upstream region in the IME1 promoter was used to detect IRT2. To control for loading, membranes were also probed for SCR1. c IRT2 expression in S288C diploid cells (FW631) during entry into meiosis. Cells were grown till saturation in rich medium, and subsequently shifted to SPO. Samples were taken at the indicated time points. IRT2 levels were quantified by reverse transcription and quantitative PCR. The signals were normalized to ACT1 levels. The means \pm SEM of $n=2$ experiments are shown. $\mathbf{d}$ Scheme of IME1 and RME1 alleles used in $\mathbf{e}$ and $\mathbf{f}$. e Quantification of cells that completed meiotic divisions (MI + MII) in diploid S288C cells that were either wild type (FW631), expressed IRT2 from the inducible CUP1 promoter (pCUP-IRT2) (FW2668) or harbored a deletion of RME1 (rme1A, FW1497). Cells were grown as described in $\mathbf{c}$, at $2 \mathrm{~h}$ in SPO, pCUP-IRT2 cells were either not treated ( $-\mathrm{Cu}$ ) or treated with copper sulfate $(+\mathrm{Cu})$. Cells were fixed after $72 \mathrm{~h}$ in SPO, stained, and DAPI masses of $n=200$ cells were counted. Cells with two or more masses were considered to have completed at least one meiotic division. Means \pm SEM of $n=5$ experiments are shown. ${ }^{\star \star \star} p<0.0005$; ${ }^{* \star \star \star} p<0.0001$ (Student's $t$ test). $\mathbf{f}$ Quantification of cells that completed meiotic divisions (MI + MII) in SK1 diploid cells that were either wild type (FW1511), pCUP-IRT2 (FW5254), rme1A (FW2340), harbored deletions in the a1 22 repressor sites of the RME1 promoter (RME1-H, FW1196), harbored pCUP-IRT2 and rme1A (FW2476), or pCUP-IRT2 and RME1-H (FW2385). Cells grown and treated as described in e. Means \pm SEM of at least $n=4$ experiments are shown. ${ }^{\star} p<0.05 ;{ }^{* \star \star *} p<0.0001$ (Student's $t$ test)

(100\% versus 65\%) (Fig. 2a, c). We further examined whether IRT 2 controls IME1 expression in cis or in trans. We generated a heterozygous $I M E 1$ allele diploid strain with one copy harboring $p C U P-I R T 2$ together with ime1 $\Delta$ and the other copy expressing the wild-type IME1. Since expression of IRT2 $(p C U P-I R T 2,+\mathrm{Cu})$ did not improve the kinetics of meiosis compared to no expression IRT2, we conclude that IRT2 controls IME1 expression in cis (Supplementary Fig. 3a-d). Finally, we obtained evidence that $I R T 2$ represses the expression of IRT1 directly and not via Ime1. Given that IRT2 expression leads to increased expression of $I M E 1$, it is possible that Ime1 itself is responsible for repression of IRT1. To test this, we measured IRT1 expression in cells harboring a $3^{\prime}$ end mutation in IME1 (ime1-t), which impairs Ime1 function, in the presence of transcription of IRT2 ( $p C U P-I R T 2$, $+\mathrm{Cu})$. We found that IRT2 efficiently repressed IRT1 expression despite the presence of ime1-t (Supplementary Fig. 3e). In conclusion, IRT2 transcription represses $I R T 1$, and thereby promotes $I M E 1$ expression and entry into meiosis.

Imel feeds back to its own promoter and activates IRT2. IRT2 expression occurs in diploid cells only during entry into meiosis indicating that its transcription is tightly regulated. To identify transcriptional regulators of IRT2 expression, we scanned the IRT2 promoter for sequence motifs. An Ume6 binding site (tgggtggcta) was identified about $90 \mathrm{bp}$ upstream IRT2, which corresponds to $-2314 \mathrm{bp}$ of the IME1 AUG (Fig. 3a). Indeed, Ume6 directly binds to the IME1 promoter as measured by chromatin immunoprecipitation (ChIP) (Fig. 3b). Cells lacking Ume6 motif did not show binding Ume6. Further, the binding of Ume6 was independent of IME1 expression because in the ime1-t mutant Ume6 binding was not affected (Supplementary Fig. 4a). The sequence motif is also present in related Saccharomyces species (Fig. 3a). Ume6 normally functions as a transcriptional repressor, however, in the presence of Ime1, Ume6 turns into a transcriptional activator ${ }^{26,27}$. Importantly, the expression of genes required for meiosis is controlled by Ume ${ }^{26,28}$. To examine how Ume6 and Ime1 control IRT2, we measured IRT2 expression in cells containing a deletion of the Ume6 motif ( $P I M E 1-\Delta u 6)$, ime1$t$, or both modifications. In pIME1- $\Delta u 6$ cells, baseline IRT2 expression was detected (Fig. 3c, compare lanes 1-3 with 4-6). No IRT2 expression was observed in ime1-t cells, while the expression of the double mutant was comparable to pIME1- $\Delta u 6$ (Fig. 3c, compare lanes 7-9 with 10-12 and 4-6). If IRT2 expression depends on Imel expression levels then induction of IME1 leads to increased IRT2 transcription. To test this, we 
a

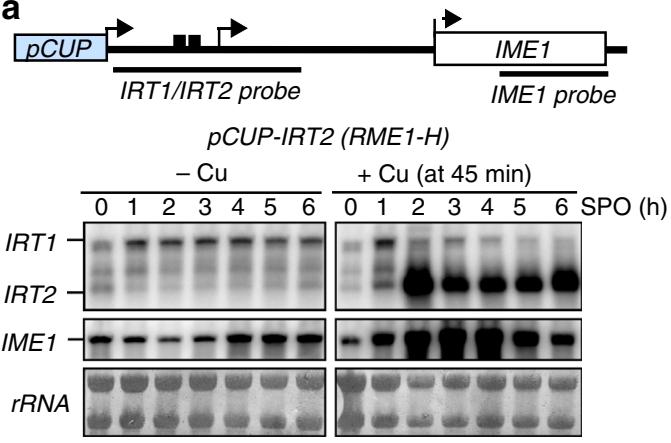

b

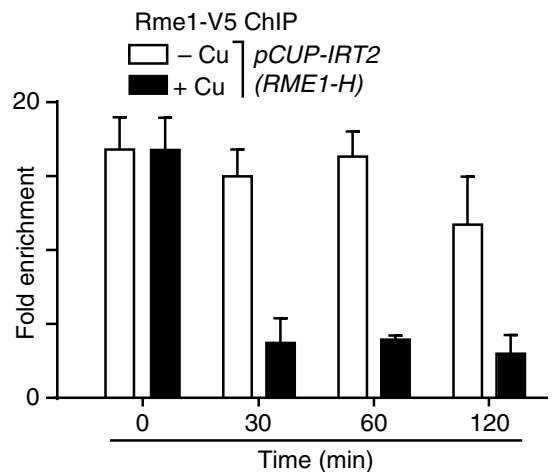

C

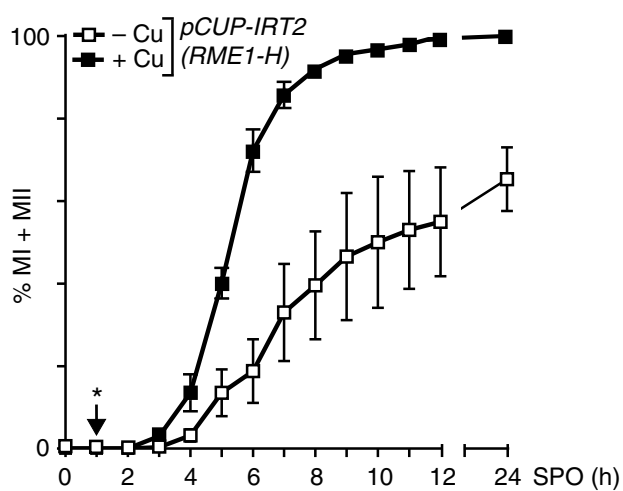

Fig. 2 IRT2 transcription interferes with Rme1 binding, and promotes IME1 expression a IRT2, IRT1, and IME1 expression in diploid cells harboring PCUP-IRT2 and RME1-H tagged with the V5 epitope tag (FW2060) by northern blot. Cells were pre-grown in rich medium, pre-sporulation medium, before shifted to SPO and were either not treated $(-\mathrm{Cu})$ or treated with copper sulfate $(+\mathrm{Cu})$ after $45 \mathrm{~min}$ in SPO. Samples were taken at the indicated time points. Northern blot membranes were hybridized with a probe that detects both IRT1 and IRT2, and a probe that detects IME1. As a loading control, the ribosomal RNA is displayed. b Similar as a, except that binding of Rme1 to the IME1 promoter was determined by chromatin immunoprecipitation using $\mathrm{V} 5$-antibodies coupled to agarose beads in cells that were either not treated $(-\mathrm{Cu})$, or treated with copper sulfate $(+\mathrm{Cu})$. Samples were taken at the indicated time point after treatment, formaldehyde crosslinked, and chromatin extracts were prepared. Rme1DNA complexes were isolated by immunoprecipitation, and the recovered DNA fragments were quantified by qPCR using a primer pair directed against the Rme1-binding sites in the IME1 promoter. The signals were normalized to the silent mating locus (HMR), where Rme1 does not bind. The means \pm SEM of $n=4$ experiments are shown. c Similar as a, except that kinetics of meiotic divisions were determined. Means \pm SEM of $n=3$ experiments are shown. ${ }^{*}$ Indicates the time of treatment with copper sulfate measured IRT2 expression in cells harboring IME1 fused to an inducible promoter ( $p C U P-I M E 1)$. No detectable expression of IRT2 was detected when IME1 was not induced (Fig. 3d). Conversely, induction of pCUP-IME1 $(+\mathrm{Cu})$ was directly followed by increased IRT2 expression, which required the Ume6-binding site (Fig. 3d and Supplementary Fig. 4b). In conclusion, Ume6 represses IRT2, whereas Ume6 together with Ime1 activate IRT2 expression.

Ime1 changes the local chromatin environment via IRT2. Having established that Ime1 promotes IRT2 transcription, we next investigated how the feedback loop regulates the local chromatin environment. It is well-established that transcriptioncoupled chromatin changes repress cryptic and local gene expression $^{29}$. To examine chromatin changes in context of Ime1mediated IRT2 transcription, we measured nucleosome positioning at the IRT2 region using micrococcal nuclease (MNase) and quantitative PCR during entry into meiosis in absence or presence of Ime1 and IRT2 expression. In the absence of Ime1 ( $p C U P-I M E 1,-\mathrm{Cu})$, the Rme1-binding sites were unprotected from the MNase digestion, which is indicative of an active promoter (Fig. 4a). In contrast, cells in which IME1 was induced ( $p C U P-I M E 1,+\mathrm{Cu})$, and therefore IRT2 was expressed, displayed stable nucleosomes around the Rme1-binding sites in the IME1 promoter (Fig. 4a). This result indicates that transcription of IRT2 establishes repressive chromatin to prevent Rmel recruitment. Given that Rme1 promotes IRT1 transcription and therefore an open chromatin state near the Rmel-binding sites, we next examined how Rmel expression affects the nucleosome positioning. Interestingly, stable nucleosomes were also detected, but less prominent, in $R M E 1-H$ cells indeed suggesting that Rme1 and IRT2 have an opposing effect on nucleosome assembly in the upstream region of the IME1 promoter (Supplementary Fig. 5a, right panel). In line with this observation, we found that Rmel binding was strongly reduced when IRT2 transcription was activated by Ime1 (Fig. 4b). As a consequence, IRT1 levels were reduced (Fig. 4c, compare lanes 3-9 with 10-16).

Transcription-coupled chromatin changes are often accompanied with post-translational modifications of histones that have an important function in establishing repressive chromatin ${ }^{29}$. Previous work showed that in haploid cells IRT1-mediated repression of IME1 requires Set2-dependent methylation of histone $\mathrm{H} 3$ lysine 36, and the histone deacetylase complex Set3C[2]. Haploid cells lacking Set2 and Set3 fail to repress IME1 via $I R T 1$, and undergo a lethal meiosis. In order to examine whether Set 2 and Set3 also control IME1 expression in diploid cells, we measured IRT2, IRT1, and IME1 expression in set2 $\triangle$ set $3 \Delta$ cells harboring $p R M E 1-H$. As expected, IME1 expression was increased in set $2 \Delta$ set $3 \Delta$ cells because IRT1-mediated repression of IME1 is impaired in this mutant background (Fig. 4d). As a consequence, IRT2 expression was also elevated (Fig. 4d, compare lanes 7-11 with 18-22). Conversely, IRT1 expression decreased in the set $2 \Delta$ set $3 \Delta$ suggesting that IRT2-mediated repression of IRT1 does not require Set2 and Set3 (Fig. 4d, compare lanes 7-11 with 18-22). In line with this observation, histone $\mathrm{H} 3$ lysine 36 methylation was not detected at IRT2 while being transcribed (Supplementary Fig. 5b). IRT2mediated repression of IRT1 was also not impaired in set $2 \Delta \operatorname{set} 3 \Delta$ mutant cells when we expressed IRT2 from the CUP inducible promoter ( $p C U P-I R T 2)$ (Supplementary Fig. 5c). We conclude that Set2 and Set3 regulate IRT1-mediated repression of IME1 also in diploid cells, but are not important for IRT2-mediated repression of IRT1. Taken together, these results show that Ime1-mediated activation of IRT2 changes the local chromatin environment. 
a

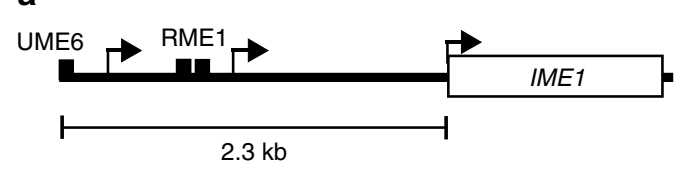

\begin{tabular}{ll}
\multicolumn{2}{c}{ UME6 (tgggcggcta) } \\
S. cerevisiae & -2314 \\
S. bayanus & -2356 (taggcggcta) \\
S. mikatae & -2310 \\
S. paradoxus & -2273 \\
S. kudriavzevii & -2272
\end{tabular}

b

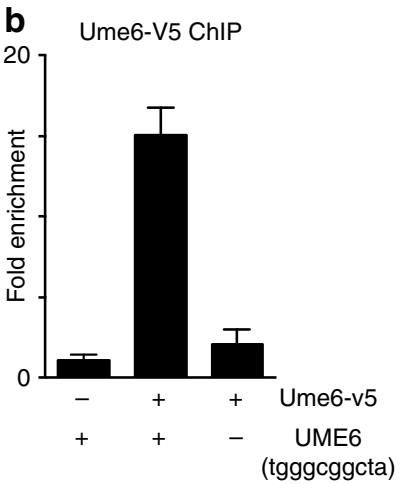

C

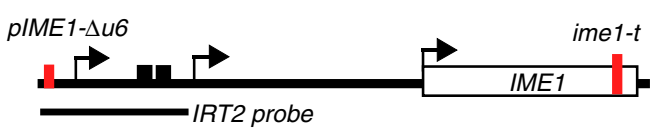

d
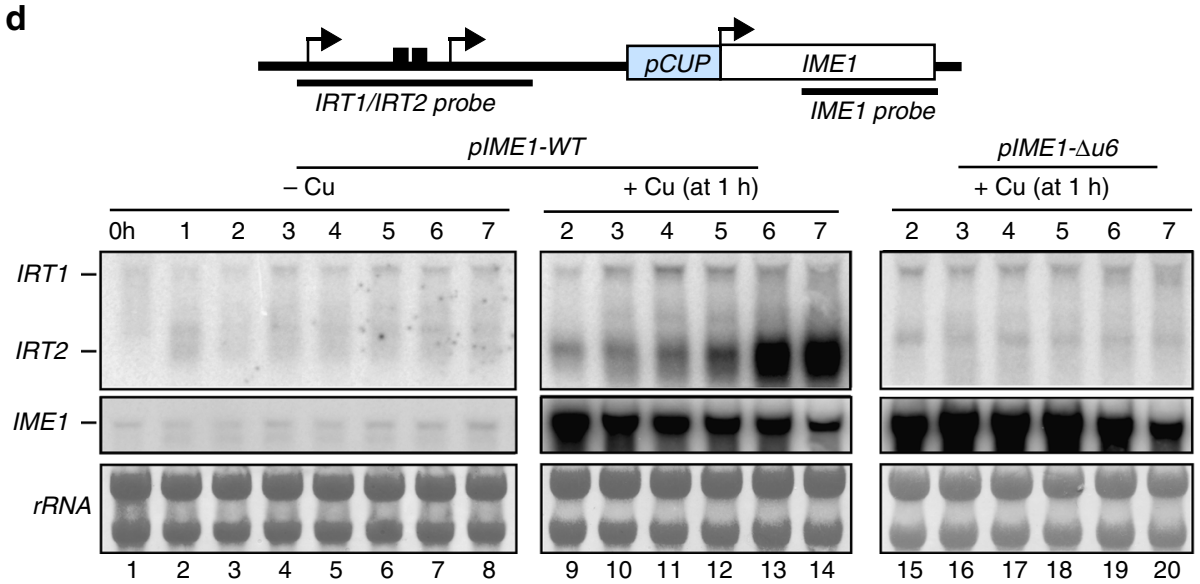

Fig. 3 Ime1 and Ume6 control IRT2 expression. a Schematic overview of the IME1 locus indicating the position of the Ume6-binding site (left). Nucleotide coordinates of the Ume6 site relative to IME1 AUG in different Saccharomyces species (right). b Binding of Ume6 to the IME1 promoter measured by chromatin immunoprecipitation using V5 tagged Ume6 (FW2978). A wild-type (FW1509) and an Ume6-binding deletion mutant (pIME1- 4 u6, FW2000) strains were also included in the analysis. The means \pm SEM of $n=3$ experiments are shown. c Northern blot of IRT2 expression in cells that were pregrown in rich medium and pre-sporulation medium, before shifted to SPO. Wild-type (FW1511), single, and double mutants harboring pIME1- $\Delta$ u6 and/or a $3^{\prime}$ end mutation in IME1 (ime1-t) (FW2449, FW2370, and FW2571) strains were used for the analysis. To control for loading, the membrane was also probed for SCR1. d IRT1, IRT2, and IME1 expression detected by northern blot in cells expressing IME1 from the copper-inducible promoter (pCUP-IME1, FW3006). pIME1- $\Delta u 6$ (FW2842) cells were also included in the analysis. Cells were pre-grown in rich and pre-sporulation medium before shifted to SPO and were either not treated $(-\mathrm{Cu})$ or treated with copper sulfate $(+\mathrm{Cu})$ at $1 \mathrm{~h}$ in SPO. Northern blot membranes were hybridized with a probe that detects both IRT1 and IRT2, and a probe that detects IME1. As a loading control, the ribosomal RNA is displayed

Ime1 promotes its own expression. Our observation that Ime1mediated activation of IRT2 represses IRT1 expression predicts that Ime1 is able to promote its own transcription. To test this directly, we expressed one copy of IME1 from an inducible promoter ( $p C U P-I M E 1)$, and inserted a superfolder green fluorescent protein (GFP) at the N-terminus (GFP-Ime1) of IME1, which allowed specific detection of IME1 expression from the endogenous wild-type locus. The GFP-Imel signal increased during starvation showing that the construct is representative for $I M E 1$ promoter activity (Supplementary Fig. $6 \mathrm{a}, \mathrm{b}$ ). When $p C U P$ IME1 was induced $(+\mathrm{Cu})$ in cells with $R M E 1-H$, GFP-Ime1 levels increased more than fivefold compared to non-induced control cells, which required the Ume6-binding site (Fig. $4 \mathrm{e}$ and Supplementary Fig. 6c). Deleting the Ume6-binding site ( $p I M E 1-$ $\Delta u 6)$ caused an aberrant expression of IRT2 and an increased ability for cells to enter meiosis (Fig. $3 c$ and Supplementary
Fig. 7a-c), which explained the increase in GFP-Ime1 levels in pIME1- $\Delta u 6$ cells compared to control cells (Fig. $4 \mathrm{e}$ ). The results were comparable when we used cells harboring $\beta$-galactosidase IME1 promoter fusion instead of GFP-Ime1 (Fig. 4f). Thus, Ime1 promotes its own expression in trans.

Single-cell analyses of Ime1 feedback control. Population-based assays could mask changes in expression within subpopulations of cells. To circumvent this possible caveat, we combined time-lapse microscopy with microfluidics and monitored IME1 expression kinetics from a single locus (GFP-Ime1) in the absence or presence of the feedback control in single cells. The other IME1 locus expressed mCherry from an IME1 promoter lacking the IRT2 sequence ( $p I M E 1-\Delta i r t 2-m C h e r r y)$, which disrupts both IRT1 and IRT2 transcription. The pIME1- $\Delta$ irt2-mCherry served 
a

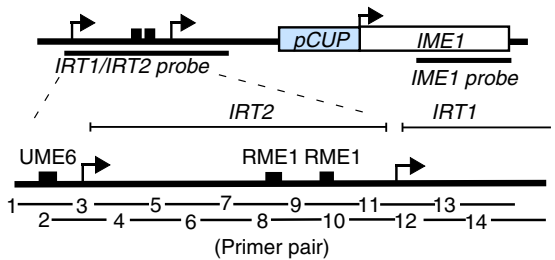

pCUP-IME1

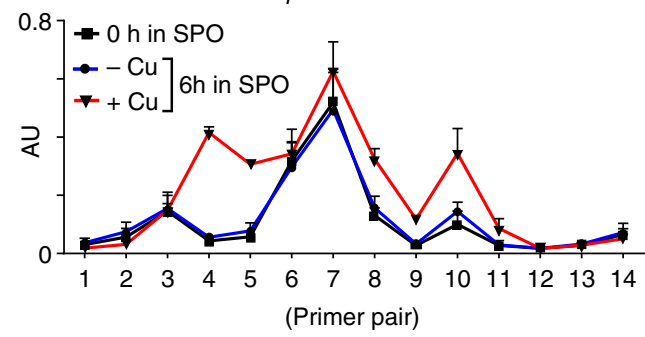

b

C
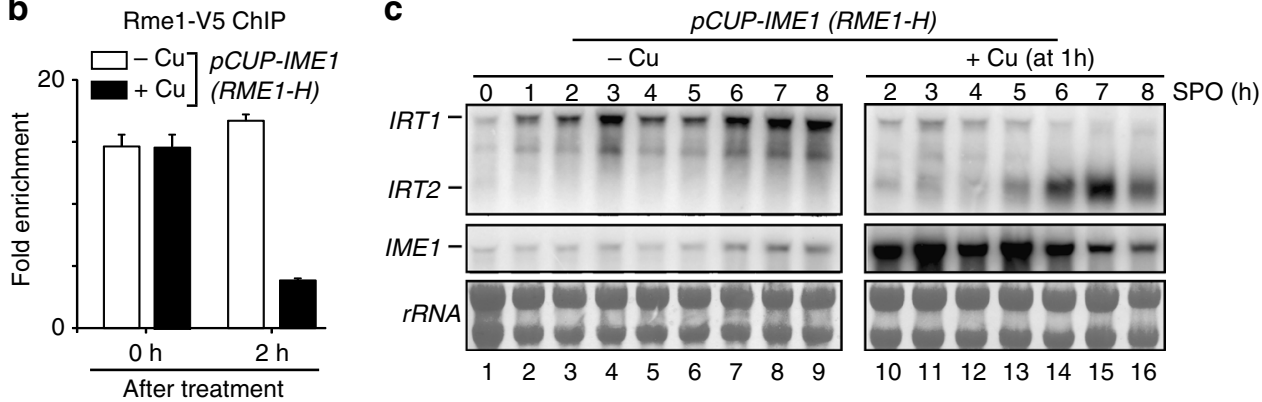

d

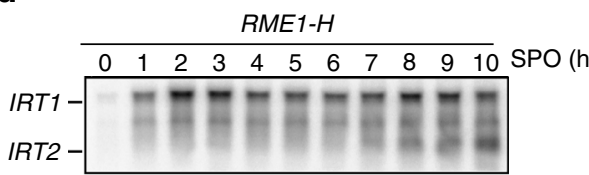

RME1-H

set2 2 set3 $\Delta$

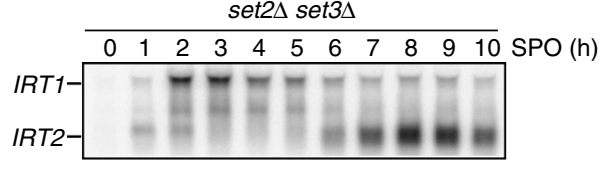

IME1- $------1-1-$

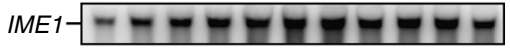

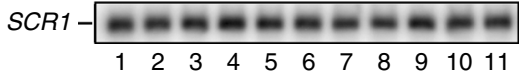

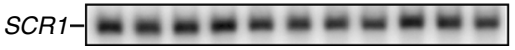

1213141516171819202122

e

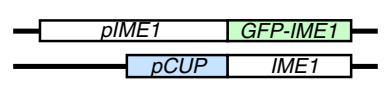

$\mathbf{f}$

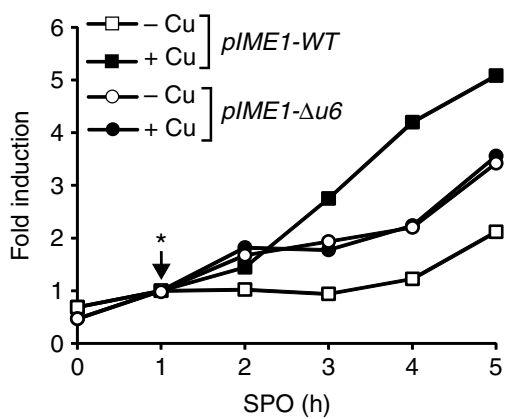

Fig. 4 Ime1 changes local chromatin via IRT2 and promotes its own expression. a Diploid cells harboring pCUP-IME1 (FW3006) were grown in rich and presporulation medium before shifted to SPO, and were either not treated $(-\mathrm{Cu})$ or treated with copper sulfate $(+\mathrm{Cu})$ after $1 \mathrm{~h}$ in SPO. Samples were taken at 0 and $6 \mathrm{~h}$ in SPO. Chromatin extracts were treated with micrococcal nuclease (MNase). Mononucleosome DNA fragments were isolated and quantified using 14 primers pairs. The signals were normalized to a no MNase input. Means \pm SEM of $n=3$. b Diploid cells with pCUP1-IME1 and RME1-H-V5 (FW1366) were induced to enter meiosis and were either not treated $(-\mathrm{Cu})$ or treated $(+\mathrm{Cu})$ after $1 \mathrm{~h}$ in SPO. Samples for chromatin immunoprecipitation were taken at 0 or $2 \mathrm{~h}$ after induction, and quantified by qPCR. The signals were normalized to the silent mating locus (HMR). Means \pm SEM of $n=3$. c $I R T 1$, IRT2, and IME1 expression in cells harboring RME1-H and pCUP-IME1 (FW2270). Cells were grown as described in a. Northern blot membranes were hybridized with probes that detects IRT1, IRT2, and IME1. As a loading control, the ribosomal RNA is shown. d IRT1, IRT2, and IME1 expression in diploid cells harboring RME1-H (FW1196) or RME1-H together with the set2 $\Delta$ set3 $\Delta$ mutant (FW1312) during entry in meiosis. Cells were grown and samples were taken as described in c. Northern blot membrane was probed for IRT1, IRT2, and IME1. SCR1 expression was used as loading control. e Cells containing one copy of

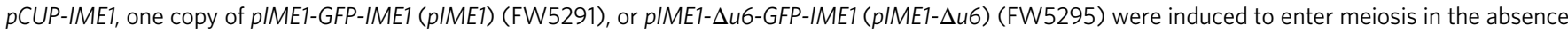
$(-\mathrm{Cu})$ or presence $(+\mathrm{Cu})$ of IME1 expression. Signals were quantified $(n=100$ cells) per time point. Means \pm error bars represent the $95 \%$ confidence interval. f Cells containing RME1-H and one copy of $p$ CUP-IME1, one copy of pIME1-LacZ (FW5337), or a mutant pIME1-EIt-LacZ plasmid lacking part of the IRT2 sequence including the Ume6 motif (FW5341) were induced to enter meiosis. The graph displays the ratio of $\beta$ galactosidase activity signals from IME1 induced samples versus not-induced samples. Means \pm SEM of $n=3$. *Treatment with copper sulfate 

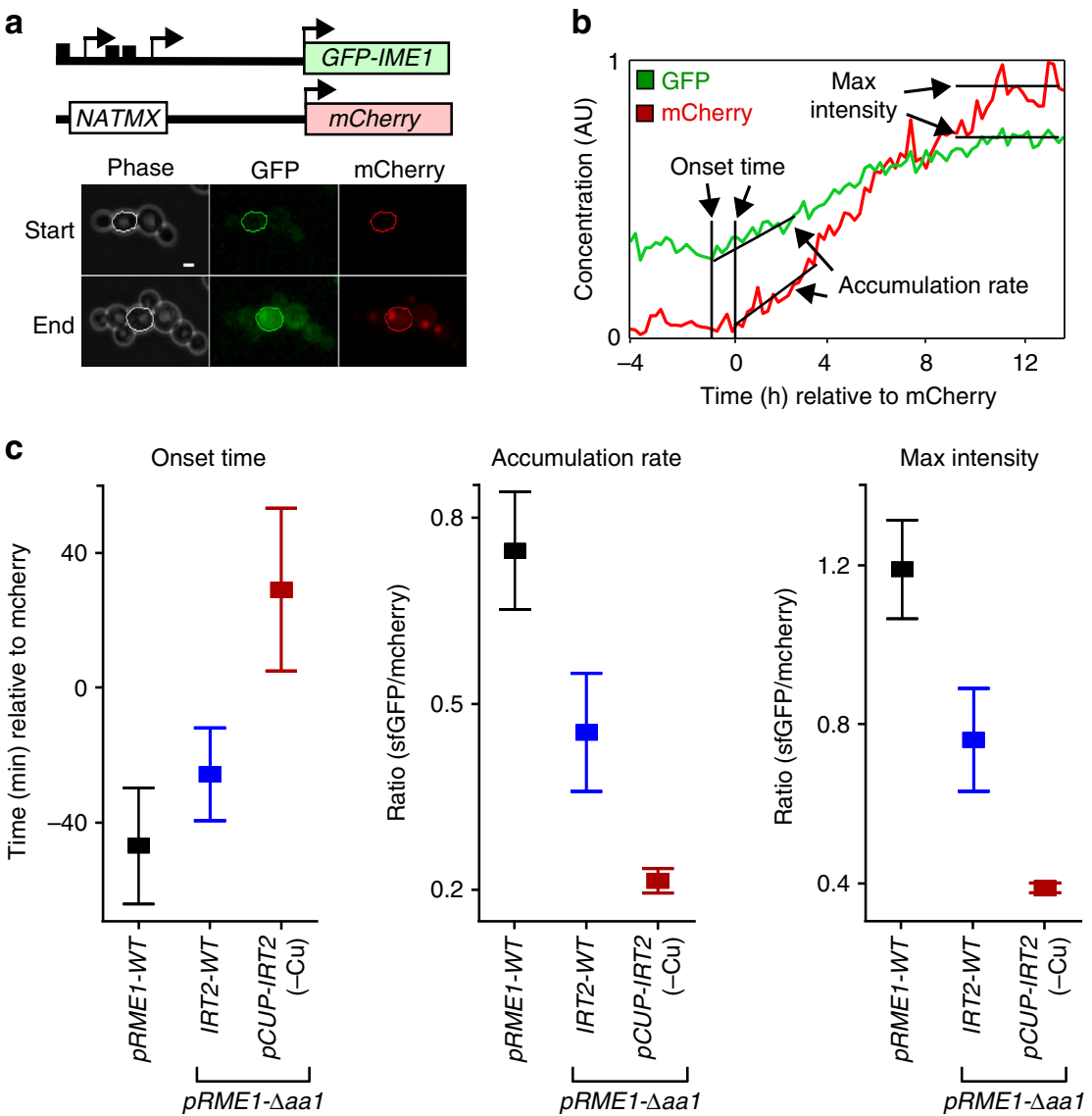

Fig. 5 Single-cell analysis of the IME1, IRT2, and IRT1 feedback cascade. a Schematic overview of IME1 locus used for time-lapse microscopy (top). Diploid cells were heterozygous for the IME1 locus: one copy of GFP fused to N-terminus of IME1 (pIME1-GFP-IME1) and one copy expressing the IME1 promoter fused to mCherry lacking the IRT2 sequence (pIMET- $\Delta$ irt2-mCherry). Cells were grown to log phase in synthetic complete media loaded into a microfluidic device, induced to enter meiosis and imaged for up till $50 \mathrm{~h}$ (see supplemental information for details). Example images of phase, GFP, and mCherry of a single cell taken at start and end of a time-lapse experiment (bottom). The scale bar in right bottom corner represents $3.2 \mu \mathrm{m}$. b Example of traces of a single cell. GFP and mCherry fluorescence signals were monitored and overall signals were scaled (see supplemental information for details). The graph also displays the time of initiation of expression (onset time), the rate of accumulation, and maximum levels (max intensity) of pIME1-GFP-IME1 and pIME1-

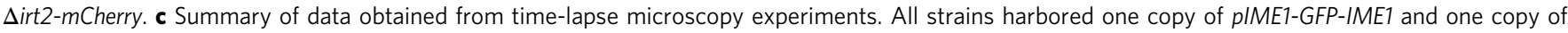

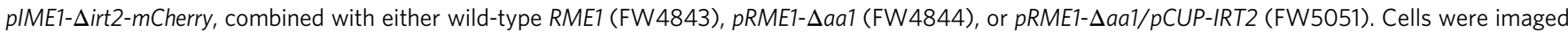
and GFP and mCherry fluorescence signals were quantified. Mean onset times, rate of accumulation, and max intensity were determined. The means \pm SEM of $n=58$ (FW4843), $n=88$ (FW4844), and $n=64$ (FW5051) cells are shown. All pairwise differences, except between FW4843 and FW4844 (left panel only), are statistically significant; $p<0.001$ (Kolmogorov-Smirnov test)

as an internal control and was used for normalizing the GFPIme1 signal (Fig. 5a). In addition, we mimicked RME1 expression of S288C by deleting only the proximal a1a2 repressor binding site in SK1 diploid cells ( $p R M E 1-\triangle a a 1)$. Three parameters were measured from each single-cell GFP and mCherry trace: the time of IME1 induction (onset time), rate of accumulation, and maximum expression of IME1 (max intensity) (Fig. 5b and Supplementary Fig. 8). Cells containing $p R M E 1-\triangle a a 1$ had a lower IME1 accumulation rate and lower max intensity compared to cells wild type for $P R M E 1$ confirming that increased IRT1 inhibits IME1 (Fig. 5c). Importantly, cells where IME1 was not able to feedback to its own promoter $(p C U P-I R T 2,-\mathrm{Cu})$ displayed a 60 min delay in onset of $I M E 1$, a twofold lower rate of accumulation, and a twofold lower max intensity. These data illustrate that the feedback loop consisting of Ime1, IRT2, and IRT1 is critical for the timing of Ime1 induction and the rate of Ime1 accumulation.

The Ime1 feedback loop is critical in yeasts expressing RME1. Our data demonstrate that Imel promotes its own expression by activating $I R T 2$, which in turn represses IRT1 and thereby de- represses IME1. Thus, in order for the feedback circuit to function, it requires expression of IRT1 (Supplementary Fig. 2a). Indeed, the activator of IRT1, RME1, is expressed in a large proportion of diploid yeast isolates, including the S288C strain background ${ }^{21-23}$. To examine the physiological importance of the regulatory circuit consisting of Ime1, IRT2, and IRT1 more closely, we measured IME1 expression in S288C cells in the absence or presence of the feedback loop by modulating IRT2 expression. Since S288C cells enter meiosis asynchronously, we monitored IME1 expression using single-molecule RNA fluorescent in situ hybridization (smFISH) in single cells (Fig. 6a and Supplementary Fig. 9). When we repressed IRT2 expression ( $p C U P-I R T 2,-\mathrm{Cu})$, the fraction of cells expressing high levels of IME1 ( $>40$ copies per cell) decreased (2\% compared to $13 \%$ for the wild type) (Fig. $6 \mathrm{~b}$ ). The fraction of cells harboring $>40$ IME1 transcripts per cell increased when IRT2 expression was elevated (pIME1- $\Delta u 6)(28 \%$ compared to $13 \%$ for the wild type) (Fig. $6 \mathrm{~b}$ and Supplementary Fig. 7). The changes in the distribution of IME1 expression among single cells were also reflected in the fraction of cells that completed meiosis (Fig. 6c). In the absence of IRT2 expression $(p C U P-I R T 2,-\mathrm{Cu})$, the fraction of cells completing meiosis was 
a

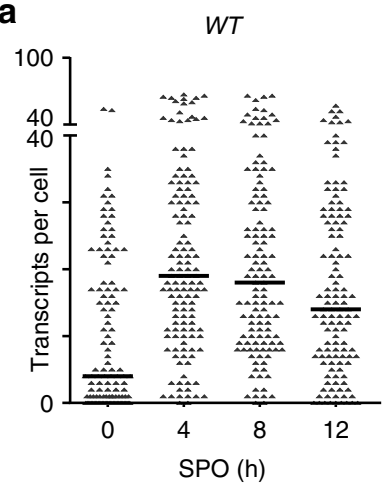

b

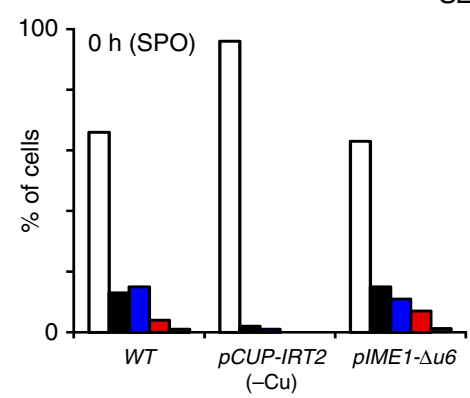

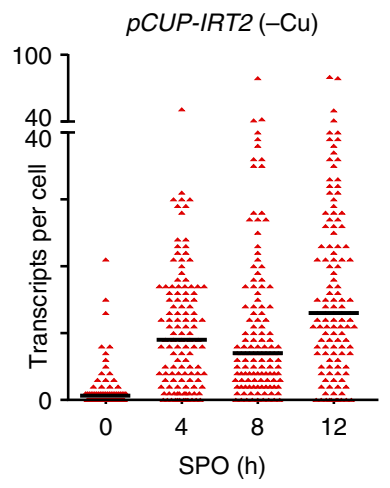

$\mathrm{S} 288 \mathrm{C}$

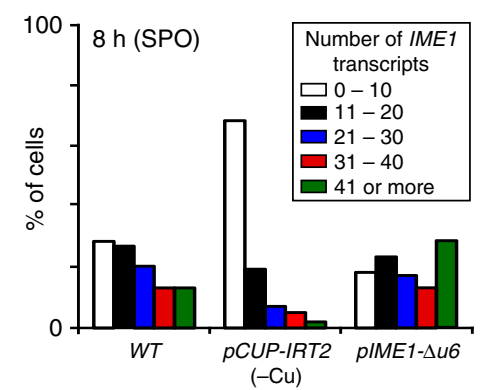

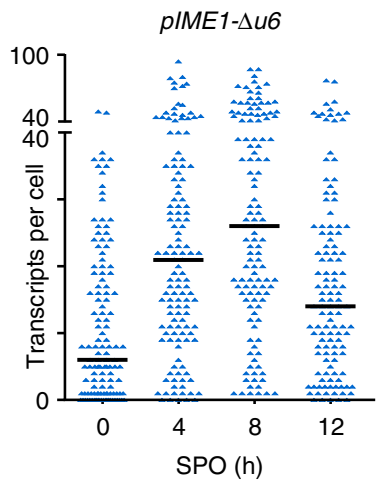

C

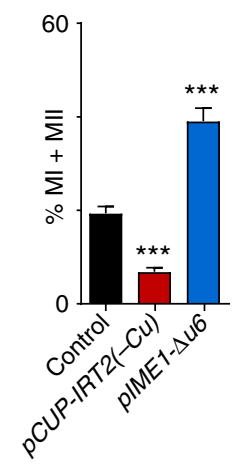

Fig. 6 Distribution of IME1 expression among single S288C cells in the presence or absence of IRT2 transcription. a Distribution of IME1 transcripts levels among single cells during entry into meiosis in S288C as detected by single-molecule RNA fluorescence in situ hybridization. Wild-type (WT) (FW631), pCUP-IRT2 (FW2668), and pIME1- $\Delta u 6$ (FW1390) cells were grown in rich medium till saturation and subsequently shifted to SPO. Samples were taken at the indicated time points, fixed, and hybridized with probes directed against IME1 and ACT1 mRNAs (see supplemental information for details). The black line indicates the median number of transcripts per cell for each time point. At least $n=120$ cells were used for the analysis. $\mathbf{b}$ Same as $\mathbf{a}$, but cells were binned according IME1 expression levels. c Quantification of cells that completed meiotic divisions in S288C cells described in a. Cells were fixed after $72 \mathrm{~h}$ in SPO, stained, and DAPI masses were counted. The means \pm SEM of at least $n=5$ experiments are shown. ${ }^{\star \star *} p<0.0005$ (Student's $t$ test)

$>50 \%$ reduced compared to wild-type cells (Fig. 6c). Conversely, a higher fraction of cells completed meiosis when expression of IRT2 was increased ( $40 \%$ compared to $19 \%$ for the wild type). We conclude that the regulatory circuit consisting Ime1, IRT2, and IRT1 directs the cell fate decision whether or not to enter meiosis.

Model for IME1 regulation by noncoding transcription. Having established how transcription of IRT2 and IRT1 controls IME1 expression and entry into meiosis, we next formulated our findings in a mathematical model with the aim to examine the dynamic properties of the regulatory circuit (Fig. 7, Supplementary Fig. 10 and Supplementary Note 1). Specifically, our model accounts for the dynamics of the transcription rates of IRT1, $I R T 2$, and IME1 as well as IME1 mRNA and Ime1 protein levels (Fig. $7 \mathrm{~b}$ and Supplementary Fig. 10a). The starvation signal, which is the primary signal for activation of IRT1 and IME1 transcription, was considered to be either off (0) or on (1) (Fig. 7b) ${ }^{19,30}$. We note that this simple model is sufficient to reflect the experimental data. In the absence of IRT1 and IRT2 transcription, Imel levels accumulated faster and were higher compared to the wild type, in line with the observations from the single-cell analyses (compare Fig. $5 c$ (middle and right panel) to Fig. $7 \mathrm{~b}$ (middle and right panel)). Conversely, in the absence of IRT2 transcription, Imel levels were reduced compared to wild type. The model predicts a gradual increase in IME1 transcription rates during starvation, which is in line with our observation that Imel can stimulate its own expression via IRT2 and IRT1 (Fig. 7b, middle panel).
Finally, we used our model to simulate how IRT2 and IRT1 control the dynamics of Ime1 accumulation during different periods of starvation (Fig. 7c and Supplementary Fig. 10b). We find that prolonged starvation $(5 \mathrm{~h})$ lead to almost maximum Ime1 expression for the wild-type IME1 promoter, while a short period of starvation $(1 \mathrm{~h})$ resulted in low levels of Ime1 accumulation (Fig. 7c, compare left and right panels to Fig. 7b right panel). In the absence of IRT1 and IRT2, a short period of starvation $(1 \mathrm{~h})$ displayed comparable Ime1 levels to a simulation of the wild type starved for $5 \mathrm{~h}$ (Fig. 7c, compare yellow left panel to blue line right panel). This suggests that the IRT2-IRT1-Ime1 regulatory circuit restricts Imel expression in cells exposed for starvation for short time periods. Taken together, we propose that there are possibly two functions for the feedback loop: (1) to elevate the rate of IME1 transcription during prolonged starvation and (2) to prevent misexpression of Imel when the cells starved for a short period of time.

\section{Discussion}

Cell fate decisions rely on precise expression of master regulatory genes. Here we described how in budding yeast a cluster of two lncRNAs is critical for controlling the expression of the master regulator for entry into meiosis, IME1. We demonstrate that orchestrated transcription of the two lncRNAs, IRT2 and IRT1, define a feedback cascade that ensures timely induction of Ime1 and increases the rate of Imel accumulation (Fig. 7d). Our findings also illustrate how transcription of two lncRNAs transmits the signal of an upstream promoter element to the 
a

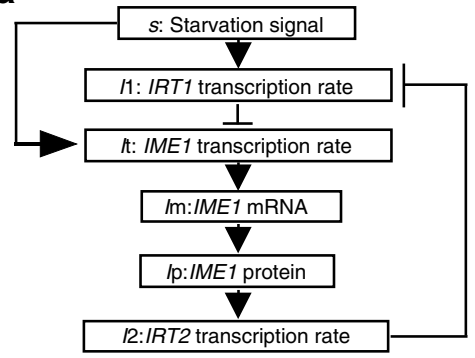

b

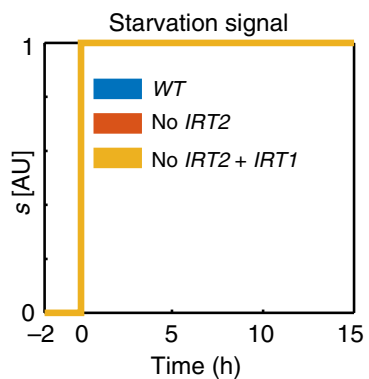

IME1

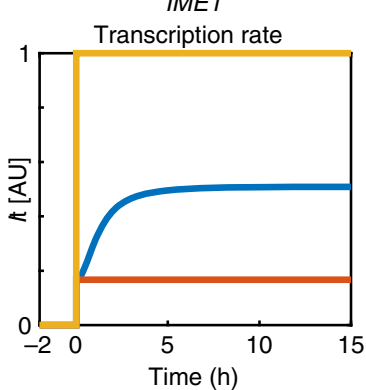

d
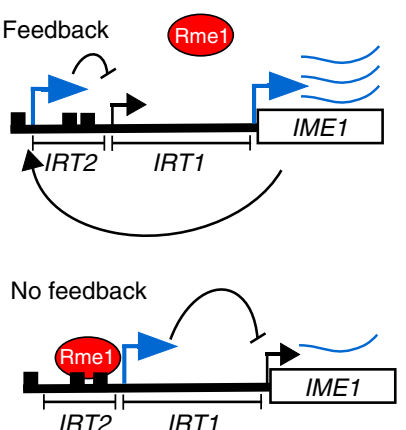

IRT2 IRT1
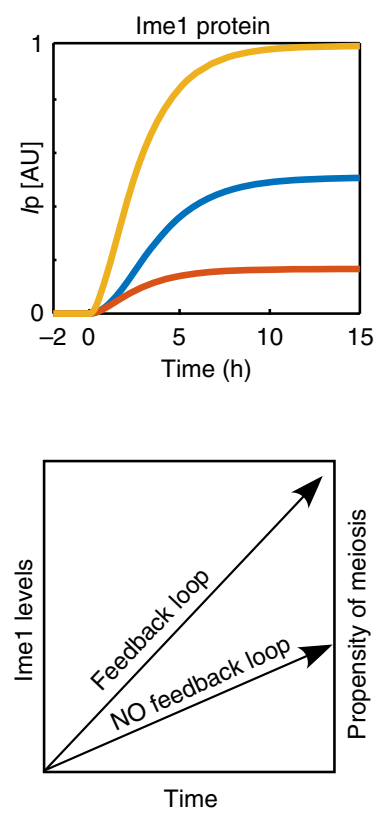

C

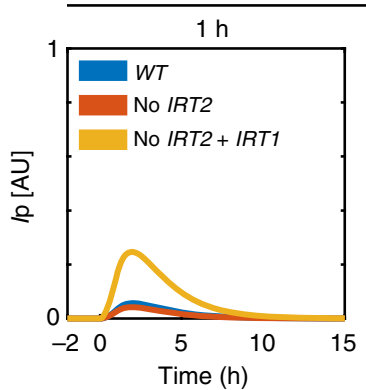

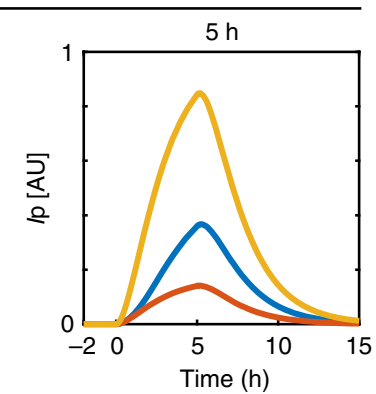

Fig. 7 Model for the regulatory circuit consisting of IME1 and the IncRNAs, IRT2, and IRT1. a Model for Ime1 regulation by IRT1, IRT2, and IME1 (see Supplemental information for details). All the variables and connections between variables are displayed. b Simulation of IME1 transcription rate (It) and Ime1 protein accumulation (Ip) prior $(s=0$, before $0 \mathrm{~h}$ ) and during starvation $(s=1)$ for the wild-type IME1 promoter, in the absence of IRT2 (no IRT2), or in the absence of IRT1 and IRT2 (no IRT2 + IRT1). The $y$ axis displays the level of s, It, or Ip in arbitrary units (AU) scaled between 0 and 1 . c Similar as b except that Ime1 protein accumulation (Ip) was simulated during starvation periods of $1 \mathrm{~h}$ and $5 \mathrm{~h}$, respectively. $\mathbf{d}$ Model of feedback cascade involving IME1, IRT2, and IRT1. In the presence of the regulatory circuit consisting of IME1, IRT2, and IRT1, Ime1 is able to stimulate its own expression. This increases the propensity for cells to undergo meiosis. Cells lacking the feedback signals from Ime1 to IRT2 and IRT1 show reduced IME1 expression and have a lower ability to enter meiosis

downstream gene. We propose that regulatory networks consisting of multiple contiguous lncRNAs can be used as a generic strategy for cells to control local gene expression dynamics.

Ime1 activates its own expression via transcription of the lncRNAs, IRT1 and IRT2. Previous work showed that transcription of IRT1 represses IME1 in haploid cells by establishing repressive chromatin in the IME1 promoter $^{2}$. We found that IRT1 is also active in diploid cells, yet the purpose IRT1-mediated repression of IME1 in this cell type is not well understood. We propose that IRT1 slows down meiotic entry till cells are "ready" to undergo meiosis. When cells are starved for nutrients, transcription of IRT1 represses accumulation of IME1. As Ime1 levels increase, it is able to feed back to its own promoter. Together with Ume6, Ime1 activates transcription of IRT2, which in turn represses $I R T 1$ and consequently more Imel is produced. It has been shown that Ime1 and Ume6 can physically interact with each other ${ }^{31,32}$. The Ume6-Ime1 interaction is required for the activation of early meiotic genes ${ }^{32}$. Thus, only in the presence of Ime1 and Ume6, IRT2 is transcribed and IRT1 is repressed. In cells where Ime1 is not able to feed back to its own promoter, the expression of IME1 is reduced and fewer cells enter the meiotic program. Thus, this regulatory switch ensures that Ime1 levels will increase only when cells are able to activate the expression of meiotic genes and progress into meiosis.

Why does Imel feed back to its own promoter via IRT2? Previous work showed that transcription of IRT1 represses a relatively large region (over $1.5 \mathrm{~kb}$ ) of the $I M E 1$ promoter requiring the upstream Rmel-binding sites ${ }^{2}$. If Imel feeds back to its own promoter downstream of the Rmel-binding sites to directly activate its transcription, it would face interference by transcription of IRT1. Our data and modeling show that repression of IRT1 transcription facilitates full activation of the IME1 promoter. We propose that transcription of $I R T 2$ is an effective way of repressing IRT1-mediated interference of the IME1 promoter, and thereby promotes Imel accumulation and entry into meiosis.

A widespread mechanism for regulating gene expression locally is by transcription-coupled chromatin changes $2,3,6,9,10,15,29,33,34$. Previous work showed that transcription of IRT1, and not the IRT1 RNA itself, is important for repression of the IME1 promoter in haploid cells ${ }^{2}$. We propose that IRT2 also uses a transcription-based mechanism for repressing IRT1. Like IRT1, transcription of IRT2 alters the local chromatin structure (Fig. 4a), and inhibits binding of a transcriptional activator to the $I M E 1$ promoter (Fig. $2 \mathrm{~b}$ and Fig. $4 \mathrm{~b}$ ). In addition, we find that the repression of IRT1 by IRT2 works in cis only (Supplementary Fig. 3), suggesting that the IRT2 RNA itself does not contribute to the repression mechanism. It is possible, however, that the IRT1 and IRT2 nascent transcripts contribute to repression of IME1 and IRT1, respectively. For example, it was shown recently that histone methyltransferases, Set1 and Set2, interact with nascent mRNAs ${ }^{35,36}$. Interestingly, both enzymes are also important for IRT1-mediated repression of IME1, but not for repression of IRT1 by IRT2 transcription ${ }^{2}$. More work is needed to dissect roles of nascent RNAs and chromatin factors in facilitating the regulatory circuit consisting of Ime1, IRT2, and IRT1.

Our observations of the IME1 locus raise the question how often transcription of multiple lncRNAs influences the expression of nearby coding genes. In budding yeast, cryptic unstable transcripts (CUTs) and stable unannotated transcripts (SUTs) are widely expressed ${ }^{37,38}$. Throughout meiosis, CUTs and SUTs, also known as meiotic unannotated transcripts (MUTs), are also transcribed extensively ${ }^{24}$. The IRT1 and IRT2 transcripts were identified as a SUT and a MUT, respectively. Given that the yeast 
genome is gene-rich and CUTs are frequently transcribed in the opposite direction nearby of adjacent genes, it is not surprising that a high percentage of genes express at least one CUT or SUT within $<400 \mathrm{bp}$ distance of their coding sequence (Supplementary Fig. 11$)^{37,38}$. Interestingly, we find that $8 \%$ of genes express more than two CUTs or SUTs within its proximity. Apart from IME1, the expression of at least two other genes is controlled by multiple lncRNAs, albeit by different mechanisms. At the FLO11 locus, two overlapping lncRNAs are expressed adjacent to the FLO11 gene, where they regulate a toggle switch for FLO11 expres$\operatorname{sion}^{39,40}$. In fission yeast, a cascade of overlapping lncRNAs is required for the activation of fbp1 expression ${ }^{5}$. Taken together, regulation of local gene expression by multiple lncRNAs is not limited to IME1 locus and may be widespread.

Like in yeast, in mammalian cells, lncRNAs are also expressed pervasively, and often nearby coding genes ${ }^{41-43}$. Several loci have been described where transcription of a single lncRNA regulates a nearby coding gen $e^{15,44,45}$. In addition, genome-wide approaches have also been used to identify loci where transcription of lncRNAs controls local gene expression ${ }^{4,46}$. Moreover, loci that express more than one lncRNAs also exits in mammalian cells. For example, the Myc oncogene expresses more than two lncRNAs upstream or downstream of its coding sequence ${ }^{47-50}$. While different functions have been attributed to the lncRNAs nearby the $M y c$ gene, perhaps transcription of these lncRNAs influences Myc expression ${ }^{47,48}$. Thus, the basic features for regulating gene expression via transcription of multiple lncRNAs are present in mammalian cells. Dissecting the mechanisms of how local gene expression is controlled through transcription of lncRNAs in yeast may facilitate the understanding in higher eukaryotes.

\section{Methods}

Yeast strains and plasmids. Yeast strains used in this paper were derived from the SK1 and the S288C strain backgrounds. The genotypes are listed in Supplementary Table 1. Gene or promoter deletions were generated using the one-step deletion protocol as described previously ${ }^{51}$. Strains harboring deletions in two or one a1 a2-binding sites present in the $R M E 1$ promoter resulting in the $R M E 1-H$ and $p R M E 1-\triangle a a 1$ alleles, respectively, were described previously ${ }^{2}$. The ime1- $t$ mutant harbors a truncation and a $3^{\prime}$ end mutation in IME1 (L325A), which was obtained through one-step integration of a NATmx cassette resulting in a deletion from 50 bp of the $3^{\prime}$-end of IME1 and two nucleotide changes within IME1. The strains harboring $R M E 1$ with three copies of V5 at C-terminus was described previously ${ }^{2}$. Plasmid p158 harboring pIME1-LacZ was previously described ${ }^{52}$. Plasmid p260 lacking part of the IRT2 sequence was generated by digestion of p158 with EcoRI and EcoNI, the ends were blunted and ligated together to generate pIME1-EIt$L a c Z$. The IME1 promoter fused to $L a c Z$ strains in Fig. 4e and Supplementary Figure 6 were generated by linearizing the plasmids, p158 and p260, with StuI and integrated at the URA3 locus. The IME1 with the N-terminal superfolder GFP (GFP) was generated using a seamless tagging approach as described previously ${ }^{53}$.

Growth and conditions. All experiments were performed at $30^{\circ} \mathrm{C}$ in a shaker incubator at 300 r.p.m. Starvation-induced synchronous sporulation were previously described ${ }^{54}$. SK1 strains were grown till saturation for $24 \mathrm{~h}$ in YPD $(1.0 \%$ $(\mathrm{w} / \mathrm{v})$ yeast extract, $2.0 \%(\mathrm{w} / \mathrm{v})$ peptone, $2.0 \%(\mathrm{w} / \mathrm{v})$ glucose, and supplemented with uracil $(2.4 \mathrm{mg} / \mathrm{l})$ and adenine $(1.2 \mathrm{mg} / \mathrm{l}))$, cells were then diluted at $\mathrm{OD}_{600}=$ 0.4 to pre-sporulation medium (BYTA) $(1.0 \%(\mathrm{w} / \mathrm{v})$ yeast extract, $2.0 \%(\mathrm{w} / \mathrm{v})$ bacto tryptone, $1.0 \%(\mathrm{w} / \mathrm{v})$ potassium acetate, $50 \mathrm{mM}$ potassium phthalate) grown for about $16 \mathrm{~h}$, subsequently centrifuged, washed with sterile miliQ water, centrifuged again, and re-suspended at $\mathrm{OD}_{600}=1.8$ in SPO $(0.3 \%(\mathrm{w} / \mathrm{v})$ potassium acetate and $0.02 \%(\mathrm{w} / \mathrm{v})$ raffinose)). S288C strains were directly shifted from saturated YPD to SPO medium following the same procedure. For Fig. If and Supplementary Figure $7 \mathrm{~b}$, SK1 strains were induced to sporulate by shifting them directly from YPD to SPO following the same procedure.

Cells harboring CUP1 promoter fused to IRT2 or IME1 ( $p C U P-I R T 2$ or $p C U P$ $I M E 1)$ were treated after $1 \mathrm{~h}$ in SPO with copper sulfate when cells were shifted from BYTA to SPO or treated after $2 \mathrm{~h}$ when cells were shifted from YPD to SPO. In Fig. $4 \mathrm{e}$ and Supplementary Figure $6,5 \mu \mathrm{M}$ of copper sulfate was used, whereas for other experiments using the SK1 strain background $25 \mu \mathrm{M}$ was used. To induce pCUP-IRT2 in the S288C strain background, $50 \mu \mathrm{M}$ was used.

For the LacZ IME1 promoter induction assay presented in Fig. 4f, cells were grown to saturation in YPD and diluted at $\mathrm{OD}_{600}=0.05$ overnight, then at around
$\mathrm{OD}_{600}=6-8$ cells were washed once with sterile millQ water and re-suspended in $\mathrm{SPO}$ at $\mathrm{OD}_{600}=1.8$.

For the live-cell imaging presented in Fig. 5 and Supplementary Figure 8, cells were grown to log phase in synthetic complete media (SCD) and loaded into a microfluidic device (Cellasic, Y04C plate) where they were exposed to SCD for an additional $2 \mathrm{~h}$, after which we exposed the cells to YNA (2\% potassium acetate, $0.25 \%$ yeast extract) for $50 \mathrm{~h}$ at constant flow rate $(0.6 \mathrm{psi})$ at $25^{\circ} \mathrm{C}$ temperature ${ }^{55}$.

Nuclei/DAPI counting. DAPI staining was used to monitor meiotic divisions throughout time courses. Cells were fixed in $80 \%(\mathrm{v} / \mathrm{v})$ ethanol, pelleted by centrifugation, and re-suspended in $100 \mathrm{mM}$ phosphate buffer $(\mathrm{pH} 7)$ with $1 \mu \mathrm{g} / \mathrm{ml}$ 4',6-diamidino-2-phenylindole (DAPI). Cells were then sonicated for a few seconds and left in the dark at room temperature for at least $5 \mathrm{~min}$. The proportion of cells containing one, two (meiosis I), three or four (meiosis II) DAPI masses were counted using a fluorescent microscope.

RT-qPCR. To quantify IRT1, IRT2, and IME1 RNA levels in S288C and SK1 strain backgrounds, we used a reverse transcription combined with quantitative PCR (RT-qPCR). Total RNAs were isolated by acid phenol-chloroform extraction, ethanol precipitated, treated with DNAse, and further column purified (MachereyNagel). About $1 \mu \mathrm{g}$ of total RNAs were reverse-transcribed using random primers and Protoscript II (NEB), and single-stranded complementary DNAs were quantified by real-time PCR using Express SYBR green mix (Life Technologies) on a 7500 Fast Real-Time PCR system (Life Technologies). The signals were normalized to ACT1 mRNA levels. Oligo nucleotide sequences used for RT-qPCR experiments are displayed in Supplementary Table 2.

Chromatin immunoprecipitation. Chromatin immunoprecipitation experiments were performed as described previously ${ }^{2}$. Cells were fixed in $1.0 \% \mathrm{w} / \mathrm{v}$ formaldehyde for 25 minutes at room temperature and quenched with $100 \mathrm{mM}$ glycine. Cells were lysed in FA lysis buffer (50 mM HEPES-KOH, pH 7.5, $150 \mathrm{mM}$ $\mathrm{NaCl}, 1 \mathrm{mM}$ EDTA, $1 \%$ Triton X-100, 0.1\% Na-deoxycholate, $0.1 \%$ SDS, and protease cocktail inhibitor used as recommended by the manufacturer (complete mini EDTA-free, Roche)) using beadbeater (BioSpec) and chromatin was sheared by sonication using a Bioruptor (Diagenode, 8 cycles of $30 \mathrm{~s}$ on/off). Extracts were incubated for $2 \mathrm{~h}$ with $15 \mu \mathrm{l}$ of anti-V5 agarose beads (Sigma) or $20 \mu \mathrm{l}$ of magnetic Prot A beads (Sigma) coupled with $0.5 \mu \mathrm{g}$ of a polyclonal antibody raised against Histone H3 (Ab1791, Abcam) or histone H3 trimethyl lysine 36 (Ab9050, Abcam), washed twice with FA lysis buffer, twice with wash buffer 1 (FA lysis buffer containing $0.5 \mathrm{M} \mathrm{NaCl})$, and twice with wash buffer $2(10 \mathrm{mM}$ Tris- $\mathrm{HCl}, \mathrm{pH} 8.0,0.25$ $\mathrm{M} \mathrm{LiCl}, 1 \mathrm{mM}$ EDTA, $0.5 \% \mathrm{NP}-40,0.5 \% \mathrm{Na}$-deoxycholate). Subsequently, reverse cross-linking was done in 1\% SDS-TE buffer (100 mM Tris pH 8.0, $10 \mathrm{mM}$ EDTA, $1.0 \% \mathrm{v} / \mathrm{v} \mathrm{SDS}$ ) at $65^{\circ} \mathrm{C}$ overnight. After $2 \mathrm{~h}$ of proteinase $\mathrm{K}$ treatment, samples were purified and DNA fragments were quantified by real-time PCR using SYBR green mix (Life Technologies) using primers described in Supplementary Table 2. Signals were normalized over the HMR locus, which showed no binding for Ume6 or Rmel. For Supplementary figure 5b, H3K36me3 ChIP signals were normalized to histone H3 ChIP.

Micrococcal nuclease digestion qPCR. To determine the chromatin structure at the IRT2 locus, mononucleosomes were extracted and purified using a MNase digestion protocol that was described previously ${ }^{56}$. Approximately, $160 \mathrm{OD}_{600}$ units of cells were crosslinked for $25 \mathrm{~min}$ at $30^{\circ} \mathrm{C}$ and 250 r.p.m. with formaldehyde $(1 \% \mathrm{v} / \mathrm{v})$. Reaction was quenched with glycine $(125 \mathrm{mM})$. Subsequently, cells were re-suspended in $20 \mathrm{ml}$ of buffer $\mathrm{Z}$ ( $1 \mathrm{M}$ sorbitol, $50 \mathrm{mM}$ Tris- $\mathrm{HCl} \mathrm{pH} \mathrm{7.4)}$ plus $\beta$-mercaptoethanol $(10 \mathrm{mM})$ and treated with $250 \mu \mathrm{g}$ of T100 Zymolase for 60 min. Next, cells were re-suspended in $1 \mathrm{ml} \mathrm{NP}$ buffer $(0.5 \mathrm{mM}$ spermidine, $1 \mathrm{mM}$ $\beta$-mercaptoethanol, $0.075 \%$ (w/v) tergitol solution-type NP-40 detergent, $50 \mathrm{mM}$ $\mathrm{NaCl}, 10 \mathrm{mM}$ Tris-HCl $\mathrm{pH} 7.4,5 \mathrm{mM} \mathrm{MgCl}, 1 \mathrm{mM} \mathrm{CaCl}$ ), vortexed for $10 \mathrm{~s}$, and $100 \mu \mathrm{l}$ of extract was treated with $0.2 \mu \mathrm{l}$ of MNase $(2 \mathrm{mg} / \mathrm{ml}, \mathrm{NEB})$ for $30 \mathrm{~min}$ at $37^{\circ} \mathrm{C}$, the reaction was quenched with EDTA $(10 \mathrm{mM})$, and reverse crosslinked overnight in 1\% SDS-TE (100 mM Tris pH 8.0, $10 \mathrm{mM}$ EDTA, $1.0 \% \mathrm{v} / \mathrm{v}$ SDS). Samples were treated with RNase A, purified DNA fragments were separated by gel electrophoresis, and mononucleosome bands were gel purified. MNase-treated and input samples were quantified by qPCR on a 7500 FAST Real-Time PCR machine (Life Technologies) using SYBR green mix (Life Technologies). The scanning primer pairs covering the IRT2 locus and upstream region used for the analysis are available in Supplementary Table 2.

Northern blotting. We adapted a northern blot protocol that was described previously ${ }^{57}$. In short, total RNA was extracted with acid phenol:chloroform:isoamyl alcohol (125:24:1) and precipitated in ethanol with $0.3 \mathrm{M}$ sodium acetate. RNA samples were denatured in a glyoxal/DMSO mix (1 M deionized glyoxal, $50 \% \mathrm{v} / \mathrm{v}$ DMSO, $10 \mathrm{mM} \mathrm{NaPi}$ buffer $\mathrm{pH} 6.5-6.8)$ at $70^{\circ} \mathrm{C}$ for $10 \mathrm{~min}$. Denatured samples were mixed with loading buffer (10\% v/v glycerol, $2 \mathrm{mM} \mathrm{NaPi}$ buffer $\mathrm{pH}$ 6.5-6.8, $0.4 \% \mathrm{w} / \mathrm{v}$ bromophenol blue) and separated on an agarose gel $(1.1 \% \mathrm{w} / \mathrm{v}$ agarose, $0.01 \mathrm{M} \mathrm{NaPi}$ buffer) for at least $2 \mathrm{~h}$ at $80 \mathrm{~V}$. RNAs were then transferred onto nylon membranes overnight by capillary transfer. The ribosomal RNA bands were visualized by methylene blue staining. The membranes were blocked for at least $3 \mathrm{~h}$ 
at $42{ }^{\circ} \mathrm{C}$ in hybridization buffer ( $1 \% \mathrm{w} / \mathrm{v}$ SDS, $50 \% \mathrm{v} / \mathrm{v}$ deionized formamide, $25 \%$ w/v dextran sulfate, $58 \mathrm{~g} / \mathrm{l} \mathrm{NaCl}, 200 \mathrm{mg} / \mathrm{l}$ herring sperm single strand DNA, $2 \mathrm{~g} / \mathrm{l}$ BSA, $2 \mathrm{~g} / \mathrm{l}$ polyvinyl-pyrolidone, $2 \mathrm{~g} / \mathrm{l}$ ficoll, $1.7 \mathrm{~g} / \mathrm{l}$ pyrophosphate, $50 \mathrm{mM}$ Tris $\mathrm{pH}$ 7.5) before hybridization. The radioactive probes were synthesized using a Prime-It II Random Primer Labeling Kit (Agilent), a target-specific DNA template and dATP, [a-32P] (Perkin-Elmer). The oligo nucleotide sequences used to generate target-specific DNA template for amplifying the northern blot probes are displayed in Supplementary Table 2. A representative blot of at least two experimental repeats was used in all figures. The full size uncropped blots are displayed in Supplementary Figure 12.

\section{Single-molecule RNA fluorescent in situ hybridization. The smRNAFISH was} performed as described previously ${ }^{2,58}$. In short, cells were fixed with $3 \%(\mathrm{w} / \mathrm{v})$ formaldehyde overnight, treated with zymolyase and further fixed in $80 \%$ ethanol. Subsequently cells were hybridized for at least $16 \mathrm{~h}$ at $30^{\circ} \mathrm{C}$ in a buffer $(10 \% \mathrm{v} / \mathrm{v}$ formamide, $10 \% \mathrm{w} / \mathrm{v}$ dextran sulfate, $2 \mathrm{mM}$ ribonucleoside vanadyl complexes, $0.02 \% \mathrm{w} / \mathrm{v}$ RNAse-free BSA, $1 \mathrm{mg} / \mathrm{ml}$ Escherichia coli transfer RNAs, $0.3 \mathrm{M}$ sodium chloride, $0.03 \mathrm{M}$ sodium citrate) containing fluorophore labeled probes directed to IME1 (AF594) and the internal control ACT1 (Cy5). Cells were pelleted after addition of $1 \mathrm{ml}$ of wash buffer ( $10 \%$ formamide, $0.3 \mathrm{M}$ sodium chloride, $0.03 \mathrm{M}$ sodium citrate), re-suspended in $400 \mu \mathrm{l}$ of Dapi buffer $\left(5 \mu \mathrm{g} / \mathrm{ml} 4^{\prime}, 6\right.$-diamidino-2phenylindole, $10 \%$ formamide, $0.3 \mathrm{M}$ sodium chloride, $0.03 \mathrm{M}$ sodium citrate) and incubated $30 \mathrm{~min}$ at $30^{\circ} \mathrm{C}$. Cells were then pelleted, re-suspended in $1 \mathrm{ml}$ of wash buffer, incubated $30 \mathrm{~min}$ at $30^{\circ} \mathrm{C}$ before being pelleted, and re-suspended in $200 \mu \mathrm{l}$ of $0.3 \mathrm{M}$ sodium chloride, $0.03 \mathrm{M}$ sodium citrate. Cells were imaged using a $\times 100$ oil objective, Numerical aperture (NA) 1.4, on a Nikon TI-E imaging system (Nikon). DIC, DAPI, AF594 (IME1), Cy5 (ACT1) images were collected every 0.3 micron (20 stacks) using an ORCA-FLASH 4.0 camera (Hamamatsu) and NISelement software (Nikon). ImageJ software was used to make maximum intensity $Z$ projections of the images ${ }^{59}$. Subsequently, StarSearch software (http://rajlab.seas. upenn.edu/StarSearch/launch.html, Raj laboratory, University of Pennsylvania) was used to quantify transcripts in single cells. Comparable thresholds were used to count RNA foci in single cells. Only cells positive for the internal control ACT1 were used for the analysis. At least a total $n=120$ cells were counted for each experiment.

$\beta$-Galactosidase assay. Liquid ortho-nitrophenyl- $\beta$-galactoside (ONPG) assay was performed as described previously ${ }^{2}$. In short, $1 \mathrm{ml}$ of $\mathrm{OD}_{600}=1.8$ cells were pelleted and washed once with buffer Z (Phosphate buffer $\mathrm{pH} 7, \mathrm{KCl} 10 \mathrm{mM}, \mathrm{MgCl}$ $1 \mathrm{mM}$ ) and cells were snap-frozen in liquid nitrogen. Cells were chemically disrupted using Y-PER buffer (Thermo Scientific), cells were incubated with ONPG (Sigma) $(1 \mathrm{mg} / \mathrm{ml}$ in $\mathrm{Z}$ buffer plus $50 \mathrm{mM} \beta$-mercaptoethanol) till yellow coloring occurred. The reaction was quenched using sodium carbonate $(1 \mathrm{mM})$ and cell debris were cleared by centrifugation. Absorption of each sample was measured at $\mathrm{OD}_{420}$ using a 96 wells plate reader. Miller units were calculated according to a standard formula: Miller unit $=\left(\right.$ signal from plate reader $\left.\left(\mathrm{OD}_{420}\right) \times 1000\right) /($ cell density $\left(\mathrm{OD}_{600}\right) \times$ time of incubation with ONPG $\left.(\mathrm{min})\right)$. The data from the experiments represents the SEM of at least two biological experiments.

Fluorescence GFP quantification. For Fig. 4e and Supplementary Figure 6, cells were fixed with $3 \%(\mathrm{w} / \mathrm{v})$ formaldehyde for $10 \mathrm{~min}$ at room temperature, cells were washed once with phosphate-sorbitol buffer ( $0.1 \mathrm{M} \mathrm{kPi}(\mathrm{pH} 7), 1.2 \mathrm{M}$ sorbitol), resuspended in phosphate-sorbitol buffer, and stored till imaging at $4{ }^{\circ} \mathrm{C}$. Imaging was performed using a $\times 100$ oil objective, NA 1.4, on a Nikon TI-E imaging system (Nikon), and $500 \mathrm{~ms}$ exposure time for the GFP channel. Images were collected using an ORCA-FLASH 4.0 camera (Hamamatsu) and NIS-element software (Nikon). ImageJ software was used for the quantification ${ }^{59}$. The fluorescence signals were determined by quantifying the whole-cell fluorescence, which was corrected for the background fluorescence signal and auto-fluorescence signal from wild-type cells. The signals represented in Fig. 4e and Supplementary Figure 6 are relative to the $1 \mathrm{~h}$ time point.

Live-cell imaging. Cells were imaged using a Zeiss Observer Z1 microscope equipped with a motorized stage, automatic focusing hardware, and temperature control with a $\times 40$ (Zeiss EC Plan-Neofluar $\times 40 / 1.3$ Ph3 WD $=0.21$ M27, oil) phase objective every $12 \mathrm{~min}$. Exposure times were $250 \mathrm{~ms}$ for GFP and $120 \mathrm{~ms}$ for mCherry using the Zeiss Kolibri LED light system with the $470 \mathrm{~nm}$ and 540-580 LEDs at $25 \%$ intensity was used with the following filter sets for GFP: excitation: FF01-504/12-25, dichroic: FF518-Di01-25x36, emission: FF01-530/11-25 and for mCherry: excitation: FF01-563/9-25, dichroic: FF573-Di01-25x36, emission: FF01598/25-25, (all filters from Semrock). Cells were segmented and tracked using a previously published algorithm ${ }^{60}$. Fluorescent concentrations were calculated by subtracting background signals from the segmented cells and dividing with the approximated cell volumes (cell area). Activation times and slopes were calculated using custom MATLAB software (available upon request). GFP-Ime1 onset time was determined relative to pIME1- $\Delta$ irt2-mCherry onset that was used to define the time 0 . The activation rates were calculated by fitting a line to the concentration curve after the onset and finding its slope.
Determining the proximity of CUTs and SUTs to coding genes. For Supplementary Figure 11, a data set from Wery et al. ${ }^{61}$ was used. For the analysis. we searched for genes that showed expression of CUTs or SUTs within $400 \mathrm{bp}$ upstream or downstream of the coding sequence $( \pm 400 \mathrm{bp})$. An overlap of $1 \mathrm{bp}$ or more between a gene \pm 400 bp and a CUTs or SUTs was considered a positive hit in our analysis.

Data availability. The data generated in the current study are available from the corresponding author.

Received: 11 September 2017 Accepted: 24 January 2018 Published online: 22 February 2018

\section{References}

1. Hongay, C. F., Grisafi, P. L., Galitski, T. \& Fink, G. R. Antisense transcription controls cell fate in Saccharomyces cerevisiae. Cell 127, 735-745 (2006).

2. van Werven, F. J. et al. Transcription of two long noncoding RNAs mediates mating-type control of gametogenesis in budding yeast. Cell 150, 1170-1181 (2012).

3. Ard, R., Tong, P. \& Allshire, R. C. Long non-coding RNA-mediated transcriptional interference of a permease gene confers drug tolerance in fission yeast. Nat. Commun. 5, 5576 (2014).

4. Engreitz, J. M. et al. Local regulation of gene expression by lncRNA promoters, transcription and splicing. Nature 539, 452-455 (2016).

5. Hirota, K. et al. Stepwise chromatin remodelling by a cascade of transcription initiation of non-coding RNAs. Nature 456, 130-134 (2008).

6. Martens, J. A., Laprade, L. \& Winston, F. Intergenic transcription is required to repress the Saccharomyces cerevisiae SER3 gene. Nature 429, 571-574 (2004).

7. Latos, P. A. et al. Airn transcriptional overlap, but not its lncRNA products, induces imprinted Igf2r silencing. Science 338, 1469-1472 (2012).

8. Ard, R. \& Allshire, R. C. Transcription-coupled changes to chromatin underpin gene silencing by transcriptional interference. Nucleic Acids Res. 44, 10619-10630 (2016)

9. Kim, J. H. et al. Modulation of mRNA and lncRNA expression dynamics by the Set2-Rpd3S pathway. Nat. Commun. 7, 13534 (2016).

10. Hainer, S. J., Pruneski, J. A., Mitchell, R. D., Monteverde, R. M. \& Martens, J. A. Intergenic transcription causes repression by directing nucleosome assembly. Genes Dev. 25, 29-40 (2011).

11. Xue, Z. et al. Transcriptional interference by antisense RNA is required for circadian clock function. Nature 514, 650-653 (2014).

12. Camblong, J., Iglesias, N., Fickentscher, C., Dieppois, G. \& Stutz, F. Antisense RNA stabilization induces transcriptional gene silencing via histone deacetylation in S. cerevisiae. Cell 131, 706-717 (2007).

13. Stojic, L. et al. Transcriptional silencing of long noncoding RNA GNG12-AS1 uncouples its transcriptional and product-related functions. Nat. Commun. 7, 10406 (2016).

14. Uhler, J. P., Hertel, C. \& Svejstrup, J. Q. A role for noncoding transcription in activation of the yeast PHO5 gene. Proc. Natl Acad. Sci. USA 104, 8011-8016 (2007).

15. Latos, P. A. et al. Airn transcriptional overlap, but not its lncRNA products, induces imprinted Igf2r silencing. Science 338, 1469-1472 (2012).

16. Marston, A. L. \& Amon, A. Meiosis: cell-cycle controls shuffle and deal. Nat. Rev. Mol. Cell Biol. 5, 983-997 (2004).

17. Kassir, Y., Granot, D. \& Simchen, G. IME1, a positive regulator gene of meiosis in S. cerevisiae. Cell 52, 853-862 (1988).

18. Nachman, I., Regev, A. \& Ramanathan, S. Dissecting timing variability in yeast meiosis. Cell 131, 544-556 (2007).

19. van Werven, F. J. \& Amon, A. Regulation of entry into gametogenesis. Philos. Trans. R. Soc. Lond. B Biol. Sci. 366, 3521-3531 (2011).

20. Weidberg, H., Moretto, F., Spedale, G., Amon, A. \& van Werven, F. J. Nutrient control of yeast gametogenesis is mediated by TORC1, PKA and energy availability. PLoS Genet. 12, e1006075 (2016).

21. Deutschbauer, A. M. \& Davis, R. W. Quantitative trait loci mapped to singlenucleotide resolution in yeast. Nat. Genet. 37, 1333-1340 (2005).

22. Gerke, J., Lorenz, K. \& Cohen, B. Genetic interactions between transcription factors cause natural variation in yeast. Science 323, 498-501 (2009).

23. Gerke, J. P., Chen, C. T. \& Cohen, B. A. Natural isolates of Saccharomyces cerevisiae display complex genetic variation in sporulation efficiency. Genetics 174, 985-997 (2006).

24. Lardenois, A. et al. Execution of the meiotic noncoding RNA expression program and the onset of gametogenesis in yeast require the conserved exosome subunit Rrp6. Proc. Natl Acad. Sci. USA 108, 1058-1063 (2011).

25. Mitchell, A. P. \& Herskowitz, I. Activation of meiosis and sporulation by repression of the RME1 product in yeast. Nature 319, 738-742 (1986). 
26. Strich, R. et al. UME6 is a key regulator of nitrogen repression and meiotic development. Genes Dev. 8, 796-810 (1994).

27. Bowdish, K. S., Yuan, H. E. \& Mitchell, A. P. Positive control of yeast meiotic genes by the negative regulator UME6. Mol. Cell. Biol. 15, 2955-2961 (1995).

28. Williams, R. M. et al. The Ume6 regulon coordinates metabolic and meiotic gene expression in yeast. Proc. Natl Acad. Sci. USA 99, 13431-13436 (2002).

29. Venkatesh, S. \& Workman, J. L. Histone exchange, chromatin structure and the regulation of transcription. Nat. Rev. Mol. Cell Biol. 16, 178-189 (2015).

30. Moretto, F. \& van Werven, F. J. Transcription of the mating-type-regulated IncRNA IRT1 is governed by TORC1 and PKA. Curr. Genet. 63, 325-329 (2017).

31. Malathi, K., Xiao, Y. \& Mitchell, A. P. Interaction of yeast repressor-activator protein Ume6p with glycogen synthase kinase 3 homolog Rim11p. Mol. Cell. Biol. 17, 7230-7236 (1997)

32. Rubin-Bejerano, I., Mandel, S., Robzyk, K. \& Kassir, Y. Induction of meiosis in Saccharomyces cerevisiae depends on conversion of the transcriptional represssor Ume6 to a positive regulator by its regulated association with the transcriptional activator Ime1. Mol. Cell. Biol. 16, 2518-2526 (1996).

33. Chia, M. et al. Transcription of a $5^{\prime}$ extended mRNA isoform directs dynamic chromatin changes and interference of a downstream promoter. Elife. 6 , e27420 (2017).

34. Kim, T., Xu, Z., Clauder-Munster, S., Steinmetz, L. M. \& Buratowski, S. Set3 HDAC mediates effects of overlapping noncoding transcription on gene induction kinetics. Cell 150, 1158-1169 (2012).

35. Battaglia, S. et al. RNA-dependent chromatin association of transcription elongation factors and Pol II CTD kinases. Elife. 6, e25637 (2017).

36. Sayou, C. et al. RNA binding by histone methyltransferases Set1 and Set2. Mol. Cell. Biol. 37, e00165-17 (2017).

37. $\mathrm{Xu}, \mathrm{Z}$. et al. Bidirectional promoters generate pervasive transcription in yeast. Nature 457, 1033-1037 (2009).

38. Neil, H. et al. Widespread bidirectional promoters are the major source of cryptic transcripts in yeast. Nature 457, 1038-1042 (2009).

39. Bumgarner, S. L., Dowell, R. D., Grisafi, P., Gifford, D. K. \& Fink, G. R. Toggle involving cis-interfering noncoding RNAs controls variegated gene expression in yeast. Proc. Natl Acad. Sci. USA 106, 18321-18326 (2009).

40. Bumgarner, S. L. et al. Single-cell analysis reveals that noncoding RNAs contribute to clonal heterogeneity by modulating transcription factor recruitment. Mol. Cell 45, 470-482 (2012).

41. Guttman, M. et al. Chromatin signature reveals over a thousand highly conserved large non-coding RNAs in mammals. Nature 458, 223-227 (2009).

42. Hon, C. C. et al. An atlas of human long non-coding RNAs with accurate $5^{\prime}$ ends. Nature 543, 199-204 (2017).

43. Iyer, M. K. et al. The landscape of long noncoding RNAs in the human transcriptome. Nat. Genet. 47, 199-208 (2015).

44. Paralkar, V. R. et al. Unlinking an IncRNA from its associated cis element. Mol. Cell 62, 104-110 (2016)

45. Anderson, K. M. et al. Transcription of the non-coding RNA upperhand controls Hand2 expression and heart development. Nature 539, 433-436 (2016).

46. Joung, J. et al. Genome-scale activation screen identifies a lncRNA locus regulating a gene neighbourhood. Nature 548, 343-346 (2017).

47. Kim, T. et al. Long-range interaction and correlation between MYC enhancer and oncogenic long noncoding RNA CARLo-5. Proc. Natl Acad. Sci. USA 111, 4173-4178 (2014).

48. Tseng, Y. Y. et al. PVT1 dependence in cancer with MYC copy-number increase. Nature 512, 82-86 (2014).

49. Xiang, J. F. et al. Human colorectal cancer-specific CCAT1-L lncRNA regulates long-range chromatin interactions at the MYC locus. Cell Res. 24, 513-531 (2014).

50. Ling, $\mathrm{H}$. et al. CCAT2, a novel noncoding RNA mapping to 8q24, underlies metastatic progression and chromosomal instability in colon cancer. Genome Res. 23, 1446-1461 (2013).

51. Longtine, M. S. et al. Additional modules for versatile and economical PCRbased gene deletion and modification in Saccharomyces cerevisiae. Yeast 14, 953-961 (1998).

52. Jambhekar, A. \& Amon, A. Control of meiosis by respiration. Curr. Biol. 18, 969-975 (2008).
53. Khmelinskii, A., Meurer, M., Duishoev, N., Delhomme, N. \& Knop, M. Seamless gene tagging by endonuclease-driven homologous recombination. PLoS ONE 6, e23794 (2011)

54. Falk, J. E., Chan, A. C., Hoffmann, E. \& Hochwagen, A. A Mec1- and PP4dependent checkpoint couples centromere pairing to meiotic recombination. Dev. Cell 19, 599-611 (2010).

55. Piccirillo, S., White, M. G., Murphy, J. C., Law, D. J. \& Honigberg, S. M. The Rim101p/PacC pathway and alkaline $\mathrm{pH}$ regulate pattern formation in yeast colonies. Genetics 184, 707-716 (2010).

56. Rando, O. J. Genome-wide mapping of nucleosomes in yeast. Methods Enzymol. 470, 105-118 (2010).

57. Koster, M. J., Yildirim, A. D., Weil, P. A., Holstege, F. C. \& Timmers, H. T. Suppression of intragenic transcription requires the MOT1 and NC2 regulators of TATA-binding protein. Nucleic Acids Res. 42, 4220-4229 (2014).

58. Raj, A., van den Bogaard, P., Rifkin, S. A., van Oudenaarden, A. \& Tyagi, S. Imaging individual mRNA molecules using multiple singly labeled probes. Nat. Methods 5, 877-879 (2008).

59. Schneider, C. A., Rasband, W. S. \& Eliceiri, K. W. NIH image to ImageJ: 25 years of image analysis. Nat. Methods 9, 671-675 (2012).

60. Doncic, A., Eser, U., Atay, O. \& Skotheim, J. M. An algorithm to automate yeast segmentation and tracking. PLoS ONE 8, e57970 (2013).

61. Wery, M. et al. Nonsense-mediated decay restricts lncRNA levels in yeast unless blocked by double-stranded RNA structure. Mol. Cell 61, 379-392 (2016).

\section{Acknowledgements}

We are grateful to Michael Knop for the GFP tagging plasmid, and Frank Uhlmann, Paola Scaffidi, Jessica Greenwood, and the members of the CGR lab for their critical reading of the manuscript. This work was supported by CPRIT (RR150058) \& the Welch foundation (I-1919-20170325) to A.D. and by the Francis Crick Institute to F.M. and F.J. v.W., which receives its core funding from Cancer Research UK (FC001203), the UK Medical Research Council (FC001203), and the Wellcome Trust (FC001203).

\section{Author contributions}

F.M. and F.J.v.W. conceived and designed the study. F.M. performed the experiments. N E.W. and A.D. performed the time-lapse microscopy experiments, analyzed data, and provided the mathematical model. G.K. performed bioinformatics analyses for Supplementary Figures 1 and 11. F.M and F.J.v.W. analyzed data. F.M. and F.J.v.W. wrote the paper.

\section{Additional information}

Supplementary Information accompanies this paper at https://doi.org/10.1038/s41467018-03213-z.

Competing interests: The authors declare no competing financial interests.

Reprints and permission information is available online at http://npg.nature.com/ reprintsandpermissions/

Publisher's note: Springer Nature remains neutral with regard to jurisdictional claims in published maps and institutional affiliations.

\footnotetext{
Open Access This article is licensed under a Creative Commons Attribution 4.0 International License, which permits use, sharing, adaptation, distribution and reproduction in any medium or format, as long as you give appropriate credit to the original author(s) and the source, provide a link to the Creative Commons license, and indicate if changes were made. The images or other third party material in this article are included in the article's Creative Commons license, unless indicated otherwise in a credit line to the material. If material is not included in the article's Creative Commons license and your intended use is not permitted by statutory regulation or exceeds the permitted use, you will need to obtain permission directly from the copyright holder. To view a copy of this license, visit http://creativecommons.org/ licenses/by/4.0/.
}

(C) The Author(s) 2018 